\title{
Avaliação Ecotoxicológica Preliminar das Águas das Bacias Hidrográficas dos rios Tarumã, São Raimundo e Educandos
}

Déborah Oliveira RODRIGUES ${ }^{1}$, Sergio Luiz Rodrigues da SILVA², Maria do Socorro Rocha da SILVA ${ }^{3}$

\section{RESUMO}

As Bacias hidrográficas dos riosTarumá, São Raimundo e Educandos e seus afluentes estão sendo impactados, devido as influências antrópicas. Neste estudo foi realizada uma avaliação da toxicidade das águas destes ecossistemas, através de testes de toxicidade aguda com Daphnia similis e análises físico-químicas. Os resultados obtidos demostraram um maior efeito deletério sobre D. similis, nas amostras da microbacia Tarumã.

PALAVRAS-CHAVE: ecotoxicologia, toxicidade aguda, Daphnia similis,

\section{Preliminary evaluation of the toxicity in water of the Tarumã, São Raimundo and Educandos basins}

\section{ABSTRACT}

The Tarumá, São Raimundo and Educandos basins, and their tributaries, are impacted by antropic influence. This study tried to evaluate the water toxicity of the hydrographic basins, through acute toxicity bioassay using Daphnia similis as testorganism and physical and chemical analysis. The results showed that, of the three basins, the water from Tarumá caused the most deleterious effect on $D$. similis.

KEYWORDS: ecotoxicology, acute toxicity, Daphnia similis.

1 Instituto Nacional de Pesquisas da Amazônia - INPA. E-mail: deborahamazonas@yahoo.com.br

2 Instituto Nacional de Pesquisas da Amazônia - INPA. E-mail : maildosergio@yahoo.es

${ }^{3}$ Instituto Nacional de Pesquisas da Amazônia - INPA. E-mail : ssilva@inpa.gov.br 


\section{INTRODUÇÃo}

Testes ou ensaios de toxicidade são instrumentos da área de Ecotoxicologia, utilizados para a integração de dados biológicos, químicos e físico-químicos. São importantes ferramentas nos estudos ambientais, devido às limitaçôes existentes nos estudos baseados em evidências puramente químicas, das quais destacam-se: a elevada variedade de substâncias presentes em efluentes líquidos; baixa capacidade de detecção analítica; as interferências pelos fenômenos químicos de antagonismo e sinergismo que dificultam sobretudo no processo de interpretaçáo de resultados.

Os testes de toxicidade aguda são empregados para estimar a toxicidade a partir dos níveis de letalidade ou efeito sobre a capacidade de mobilidade dos organismos, em geral em curtos intervalos de tempo ( $24 \mathrm{~h} \mathrm{ou} 48 \mathrm{~h}$ ) de exposiçâo (dependendo do ciclo de vida do organismo). O teste de toxicidade aguda com Daphnia similis (ABNT, 2004) vêm sendo amplamente empregado para a avaliaçáo ecotoxicológica de sistemas límnicos, a partir de amostras da coluna d'água, inclusive com amostras de águas intersticiais dos sedimentos.

A expansão urbana no município de Manaus, em associação com processos de desmatamentos; uso nấo planejado do solo; emissões de efluentes líquidos industriais e domiciliares; além do aporte de poluentes transportados do meio urbano, mediante os sistemas de drenagem e escoamento superficial, são múltiplos fatores responsáveis pelas modificaçôes das características originais dos igarapés na mencionada regiáo.

Na década de 80, os trabalhos de Fonseca et al. (1982) e Bringel, (1986), apontavam o elevado grau de degradaçấo encontrados nos igarapés urbanos de Manaus, devido à elevada carga de matéria orgânica despejadas em suas águas. Estudos posteriores executados por Silva (1996) e Cleto Filho (1998), comprovaram o estado de deterioração destes ecossistemas por esgotos domésticos, efluentes industriais e metais pesados.

Dado o grande número de substâncias químicas existentes e seu constante incremento, torna-se praticamente impossível um estudo químico completo de todos os componentes presentes nos efluentes industriais, nas águas naturais ou nos sedimentos dos cursos d'água (Martínez-Madrid, 1997). Os compostos químicos podem atuar de diferentes maneiras sobre os seres vivos, quando se encontram separados ou combinados entre si, devido aos fenômenos de antagonismo ou sinergismo. Algumas substâncias podem produzir efeitos tóxicos em níveis inferiores aos limites de detecção analítica. Por estes motivos, evidências biológicas, ecotoxicológicas, químicas, físicas e físico-químicas devem ser empregadas de forma integrada, para a obtençâo de informaçôes objetivas, que subsidiem as decisóes nas açóes de proteção do meio ambiente.

A Resoluçáo CONAMA no 357 (BRASIL, 2005), estabelece que as possíveis interaçôes entre substâncias e a presença de contaminantes não listados na mencionada resolução, passíveis de causar danos aos seres vivos, deveráo ser investigadas utilizando-se ensaios ecotoxicológicos, toxicológicos, ou outros métodos cientificamente reconhecidos.

\section{MATERIAL E MÉTODOS}

Foram coletadas amostras de águas de superfície (aproximadamente com $15 \mathrm{~cm}$ de profundidade), com freqüência mensal, no período de setembro de 2005 a novembro de 2006, em igarapés das Bacias hidrográficas dos riosTarumá, São Raimundo e Educandos, nos locais identificados na Tabela 1 . As amostras foram transferidas para frascos de polietileno de um litro e aclimatadas a temperatura entre $4^{\circ} \mathrm{C}$ a $6^{\circ} \mathrm{C}$ em caixas térmicas durante o transporte e armazenadas posteriormente em câmara frigorífica na mesma temperatura.

Foram realizadas determinaçóes analíticas de parâmetros químicos e físico-químicos, que apresentam relação ou interferência com respostas de ensaios biológicos. Os parâmetros analisados foram: $\mathrm{pH}$, condutividade, oxigênio dissolvido, analisados pelo método eletrodométrico e dureza total, analizada pelo método complexométrico com EDTAsal dissódico.

Os níveis de toxicidade aguda foram estimados pelo método descrito na norma técnica ABNT (NBR 12713, 2004). Este método consiste basicamente, na exposição de indivíduos jovens da espécie Daphnia similis, a várias diluiçôes das amostras por um período de 48 horas. Ao final do teste, são observadas as modificaçóes na capacidade de mobilidade dos organismos. Essa resposta é utilizada em tratamentos estatísticos para a obtenção da estimativa do nível de toxicidade, expresso na forma de CE50 (Concentração Efetiva), que pode ser interpretada como a concentraçáo da amostra que causa efeito agudo a $50 \%$ dos organismos no tempo de exposição utilizado e nas condiçóes do ensaio.

Embora exista tendência para a expressão de resultados de testes de toxicidade de amostras de águas naturais, somente de forma qualitativa (presença ou ausência de toxicidade), neste estudo foram aplicados procedimentos de testes com diluiçóes (igualmente aos estudos com águas residuais e produtos químicos), para permitir a obtenção também de resultados quantitativos, evidenciando assim a magnitude da toxicidade destes sistemas hídricos, que são importantes afluentes do rio Negro.

A CE50 é uma unidade de medida de toxicidade inversa, ou seja, quanto maior o valor, menor será a toxicidade na amostra. Para a avaliaçáo da magnitude das respostas entre os locais estudados, os dados foram expressos na forma de UT (Unidades de Toxicidade), obtida mediante a expressão matemática: 
Tabela 1 - Identificação dos locais, onde foram realizadas as coletas de amostras.

\begin{tabular}{|c|c|c|c|c|c|}
\hline \multicolumn{6}{|c|}{ LOCAIS DE COLETA DE AMOSTRAS } \\
\hline IDENTIFICAÇÃO & $\begin{array}{l}\text { BACIA } \\
\text { HIDROGRÁFICA }\end{array}$ & LOCALIZAÇÃO & COORDENADAS & & \\
\hline \multirow{2}{*}{ BT1 } & \multirow{8}{*}{ TARUMÃ } & \multirow{2}{*}{ Igarapé Acará. } & LATITUDE & S & $02^{\circ} 55^{\prime} 47.7^{\prime \prime}$ \\
\hline & & & LONGITUDE & W & $59^{\circ} 58^{\prime} 57.8^{\prime \prime}$ \\
\hline \multirow{2}{*}{ BT2 } & & \multirow{2}{*}{ Igarapé BARRO BRANCO (RESERVA DUCKE). } & LATITUDE & S & $02^{\circ} 58^{\prime} 05.2^{\prime \prime}$ \\
\hline & & & LONGITUDE & W & $60^{\circ} 00^{\prime} 16.4^{\prime \prime}$ \\
\hline \multirow{2}{*}{ ВT3 } & & \multirow{2}{*}{$\begin{array}{l}\text { IGARAPÉ TARUMÃ, PROXIMIDADES DO Km } \\
30 \text { DA RODOVIA BR } 174 .\end{array}$} & LATITUDE & S & $02^{\circ} 42^{\prime} 31.5^{\prime \prime}$ \\
\hline & & & LONGITUDE & W & $60^{\circ} 02^{\prime} 57.0^{\prime \prime}$ \\
\hline \multirow{2}{*}{ BT4 } & & \multirow{2}{*}{ Igarapé Mariano } & LATITUDE & S & $02^{\circ} 55^{\prime} 36.8^{\prime \prime}$ \\
\hline & & & LONGITUDE & W & $60^{\circ} 02^{\prime} 07.2^{\prime \prime}$ \\
\hline \multirow{2}{*}{ BSR1 } & & \multirow{2}{*}{ Ponte do Conjunto PetrUS } & LATITUDE & S & $03^{\circ} 04^{\prime} 28.6^{\prime \prime}$ \\
\hline & & & LONGITUDE & W & $59^{\circ} 58^{\prime} 57.8^{\prime \prime}$ \\
\hline \multirow{2}{*}{ BSR2 } & & \multirow{2}{*}{$\begin{array}{l}\text { Área do CIRMMAN (Circulo Militar de } \\
\text { Manaus) }\end{array}$} & LATITUDE & S & $03^{\circ} 06^{\prime} 03.0^{\prime \prime}$ \\
\hline & & & LONGITUDE & W & $60^{\circ} 01^{\prime} 52.4^{\prime \prime}$ \\
\hline \multirow{2}{*}{ BSR3 } & & \multirow{2}{*}{$\begin{array}{l}\text { Proximidades da rua Senador Raimundo } \\
\text { Parente }\end{array}$} & LATITUDE & S & $03^{\circ} 04^{\prime} 09.7^{\prime \prime}$ \\
\hline & & & LONGITUDE & W & $60^{\circ} 01^{\prime} 30.4^{\prime \prime}$ \\
\hline \multirow{2}{*}{ BSR4 } & & \multirow{2}{*}{ Parque Vila Olímpica } & LATITUDE & S & $03^{\circ} 05^{\prime} 08.3^{\prime \prime}$ \\
\hline & & & LONGITUDE & W & $60^{\circ} 01^{\prime} 52.3^{\prime \prime}$ \\
\hline \multirow{2}{*}{ BSR5 } & & \multirow{2}{*}{ Proximidades da rua Saldanha Rodrigues } & LATITUDE & S & $03^{\circ} 03^{\prime} 00.8^{\prime \prime}$ \\
\hline & & & LONGITUDE & W & $60^{\circ} 01^{\prime} 28.2^{\prime \prime}$ \\
\hline \multirow{2}{*}{ BSR6 } & \multirow{4}{*}{ SÃO RAIMUNDO } & \multirow{2}{*}{ Proximidades da rua Max Teixeira } & LATITUDE & S & $03^{\circ} 02^{\prime} 44.9^{\prime \prime}$ \\
\hline & & & LONGITUDE & W & $60^{\circ} 01^{\prime} 00.9^{\prime \prime}$ \\
\hline \multirow{2}{*}{ BSR7 } & & \multirow{2}{*}{$\begin{array}{l}\text { Próximo ao Conjunto dos Sargentos e Sub- } \\
\text { Tenentes da PM. }\end{array}$} & LATITUDE & S & $03^{\circ} 03^{\prime} 04.8^{\prime \prime}$ \\
\hline & & & LONGITUDE & W & $60^{\circ} 00^{\prime} 49.9^{\prime \prime}$ \\
\hline \multirow{2}{*}{ BSR8 } & & \multirow{2}{*}{ Conjunto Rio Maracanã } & LATITUDE & S & $03^{\circ} 03^{\prime} 17.8^{\prime \prime}$ \\
\hline & & & LONGITUDE & W & $60^{\circ} 01^{\prime} 08.1^{\prime \prime}$ \\
\hline \multirow{2}{*}{ BSR9 } & & Ponte Bolivia & LATITUDE & S & $03^{\circ} 00^{\prime} 41.8^{\prime \prime}$ \\
\hline & & Ponte bollvia & LONGITUDE & W & $59^{\circ} 57^{\prime} 10.3^{\prime \prime}$ \\
\hline & & & LATITUDE & $S$ & $03^{\circ} 00^{\prime} 47.1^{\prime \prime}$ \\
\hline BSR10 & & Igarape Bolıvia & LONGITUDE & W & $59^{\circ} 57^{\prime} 46.6^{\prime \prime}$ \\
\hline RSB11 & & Jarané Rolívia (Encontro de Rairrnc) & LATITUDE & S & $03^{\circ} 00^{\prime} 42^{\prime \prime}$ \\
\hline BSRT1 & & Igarape Bollvia (Encontro de Balrros). & LONGITUDE & W & $59^{\circ} 57^{\prime} 46.6^{\prime \prime}$ \\
\hline & & & LATITUDE & S & $03^{\circ} 03^{\prime} 07.3^{\prime \prime}$ \\
\hline BSR12 & & Ponte Joao Bosco & LONGITUDE & W & $60^{\circ} 01^{\prime} 16.1^{\prime \prime}$ \\
\hline & & 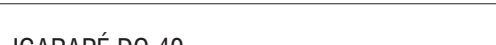 & LATITUDE & S & $03^{\circ} 08^{\prime} 0.78^{\prime \prime}$ \\
\hline BET & EUUCANDUS & IGARAPE DU 40 & LONGITUDE & W & $60^{\circ} 00^{\prime} 6.72^{\prime \prime}$ \\
\hline
\end{tabular}

Para a obtenção das estimativas dos valores de toxicidade (CE50), neste estudo foi aplicado o método de probitos (Finney, 1952; USEPA, 2002), que consiste na conversão das porcentagens de organismos afetados em probitos (unidades de probabilidade) e as concentraçóes da amostra, transformadas em logaritmos. Nos casos em que os dados não se ajustaram ao modelo de probitos, em decorrência de elevada heterogeneidade, verificada pelo teste do Chi-Quadrado, foi aplicado o teste não paramétrico Spearman-Karber, que estima a média da distribuição do $\log _{10}$ da tolerância, com ajuste dos dados, quando as proporçóes de efeito náo estáo em ordem monotonicamente crescente em função do aumento da concentração.

A correção de Abbott (Finney, 1952) foi empregada, em todos os casos, no quais houve efeito de imobilidade no tratamento controle.

Todas os valores de CE50 foram estimados com intervalo de confiança ao nível de $95 \%$. 
Os métodos estatísticos mencionados foram aplicados mediante programa de computador apropriado (Rodrigues da Silva, et al., 2004).

\section{RESULTADOS E DISCUSSÃO}

Todas as amostras dos locais BT1, BT3 e BT4 (Bacia Tarumã), apresentaram toxicidade aguda. $\mathrm{O}$ outro local (BT2) deste sistema apresentou toxicidade em $75 \%$ das amostras. Os valores tóxicos oscilaram entre 1.01 e 2.00 UT (Figura 1).

\section{BACIA TARUMÃ / TARUMÃ BASIN}

BT1

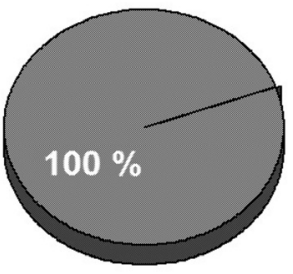

BT3

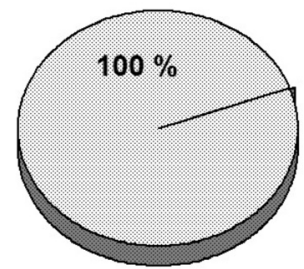

BT2

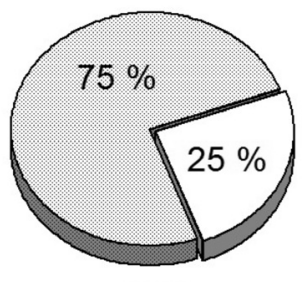

BT4

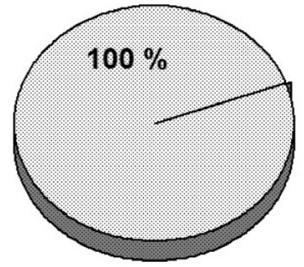

Ausência de toxicidade. / No toxicity.

Toxicidade igual ou superior a 1.0 e inferior a 2.0 UT / Toxicity greater than or equal to 1.0 and smaller than 2.0 TU.

Toxicidade igual ou superior a 2.0 e inferior a $3.0 \mathrm{UT} /$

Toxicity greater than or equal to 2.0 and smaller than $3.0 \mathrm{TU}$.

Figura 1 - Freqüência e magnitude da toxicidade (indicada pelo máximo valor detectado) observadas nas amostras da Bacia Tarumã. UT: Unidades de Toxicidade.

Na Bacia hidrográfica São Raimundo, somente o local BSR4 apresentou toxicidade aguada em todas as amostras. Em BSR1 houve detecção de toxicidade aguda em aproximadamente $29 \%$ das amostras. Os demais locais não apresentaram toxicidade aguda em suas amostras. Na Figura 2 são apresentadas as freqüências e magnitudes das respostas de toxicidade obtidas nas amostras desta bacia.

$\mathrm{Na}$ Bacia hidrográfica Educandos, somente $14 \%$ das amostras, coletadas no Igarapé do 40 (BE1), apresentaram toxicidade aguda (Figura 3).

$\mathrm{Na}$ Figura 4, estáo indicados os locais estudados, relacionando quanto às principais atividades e tipo de ocupação do solo, com a freqüência de amostras tóxicas e máximos valores de toxicidade obtidos para cada local.
BACIA SÃO RAIMUNDO / SÃO RAIMUNDO BASIN

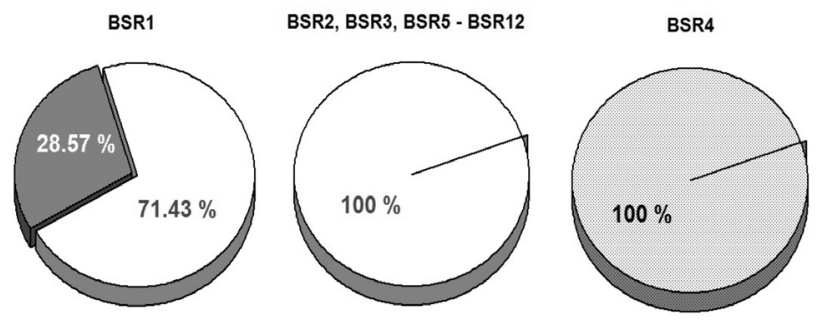

Ausência de toxicidade. / No toxicity.

Toxicidade igual ou superior a $1.0 \mathrm{e}$ inferior a $2.0 \mathrm{UT} /$

Toxicity greater than or equal to 1.0 and smaller than $2.0 \mathrm{TU}$.

Toxicidade igual ou superior a 2.0 e inferior a 3.0 UT /

Toxicity greater than or equal to 2.0 and smaller than $3.0 \mathrm{TU}$

Figura 2 - Freqüência e magnitude da toxicidade (indicada pelo máximo valor detectado) observadas nas amostras da Bacia São Raimundo. UT: Unidades de Toxicidade.

\section{BACIA EDUCANDOS / EDUCANDOS BASIN}

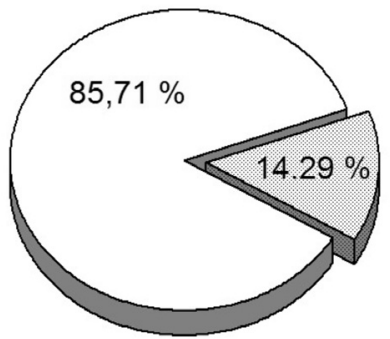

Ausência de toxicidade. / No toxicity.

Toxicidade igual ou superior a 1.0 e inferior a 2.0 UT /

Toxicity greater than or equal to 1.0 and smaller than $2.0 \mathrm{TU}$.

Toxicidade igual ou superior a 2.0 e inferior a 3.0 UT /

Toxicity greater than or equal to 2.0 and smaller than $3.0 \mathrm{TU}$.

Figura 3 - Freqüência e magnitude da toxicidade (indicada pelo máximo valor detectado) observadas nas amostras da Bacia Educandos. UT: Unidades de Toxicidade.

Em igarapés de terra firme da Amazônia Central, os valores de $\mathrm{pH}$ variam de 3.3 a 5.0 e de condutividade entre 5.2 e 28.5 $\mu$ S.cm ${ }^{-1}$ (Campos, 1994; Schmidth, 1972). Segundo Sioli (1968), valores de $\mathrm{pH}$ superiores a 6.0 indicam alteraçóes nestes ecossistemas. $\mathrm{O} \mathrm{pH}$ obtido nas amostras das águas do igarapé Barro Branco (Bacia Tarumã, local BT2), cuja nascente se encontra na Reserva Florestal Adolfo Ducke, que constitui área de floresta tropical, os valores oscilaram entre 4.7 e 5.2 (Figura 5), com baixa condutividade (Figura 6). Estas características são, portanto próprias para estes sistemas naturais, nos quais a acidez é atribuida a decomposição das substâncias húmicas provenientes da vegetação morta e os baixos teores de condutividade, geralmente inferiores a 20 $\mu$ S.cm ${ }^{-1}$ (Junk, 1983) está relacionado com a geologia da região de formação Alter do Chão (Junk, 1983; Sioli 1968). 


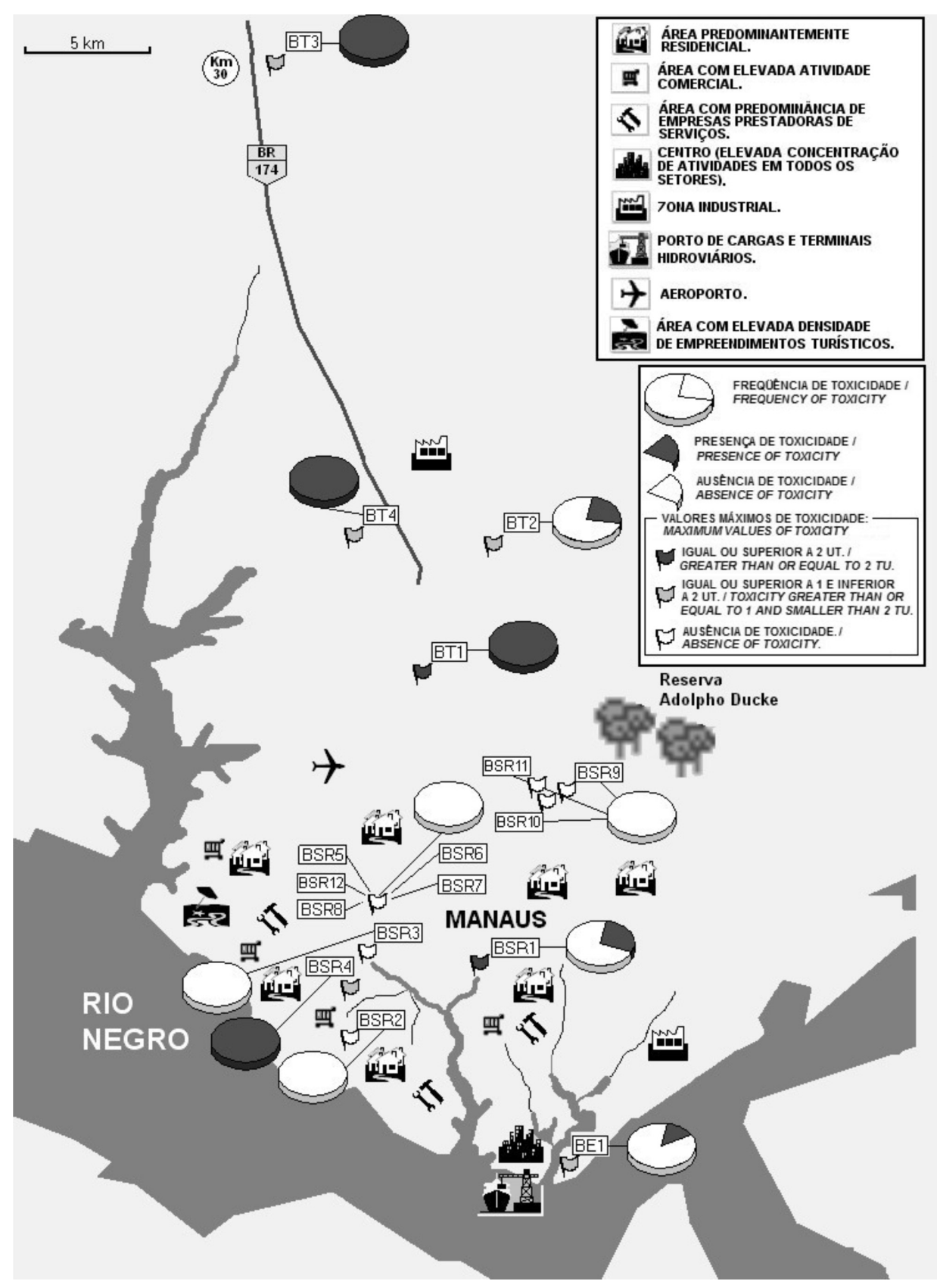

Figura 4 - Localização geográfica da área de estudo. Freqüência de amostras tóxicas e máximos valores de toxicidade obtidos nos locais de coleta.

Nos locais pertencentes as Bacias hidrográficas Educandos e São Raimundo, situadas na área urbana do município de Manaus, as amostras apresentaram $\mathrm{pH}$ superiores a 6.0, o que indica alteração de origem antrópica, anteriormente observada em estudos elaborados por Miranda (2003) e Melo (2005).

$\mathrm{Na}$ Bacia hidrográfica Educandos, nos locais de maiores impactos (BE1), as amostras apresentaram baixa variação de $\mathrm{pH}$, entre 6.7 a 7.2, o que náo se justifica relacionar o $\mathrm{pH}$ com os níveis de toxicidade, detectados em $14 \%$ das amostras.
O oxigênio possui uma solubilidade considerada moderada, onde atuam diretamente a temperatura e a pressão. Este elemento é essencial ao metabolismo de todos os organismos que possuem respiraçáo aeróbia e torna-se um dos principais parâmetros nos estudos de sistemas aquáticos. A propriedade de solubilidade do oxigênio na água é essencial para o comportamento e crescimento de organismos aquáticos (Wetzel, 1975). A Bacia hidrográfica Tarumã mostrou em todos os locais de coleta, evidencias de aeração, com 

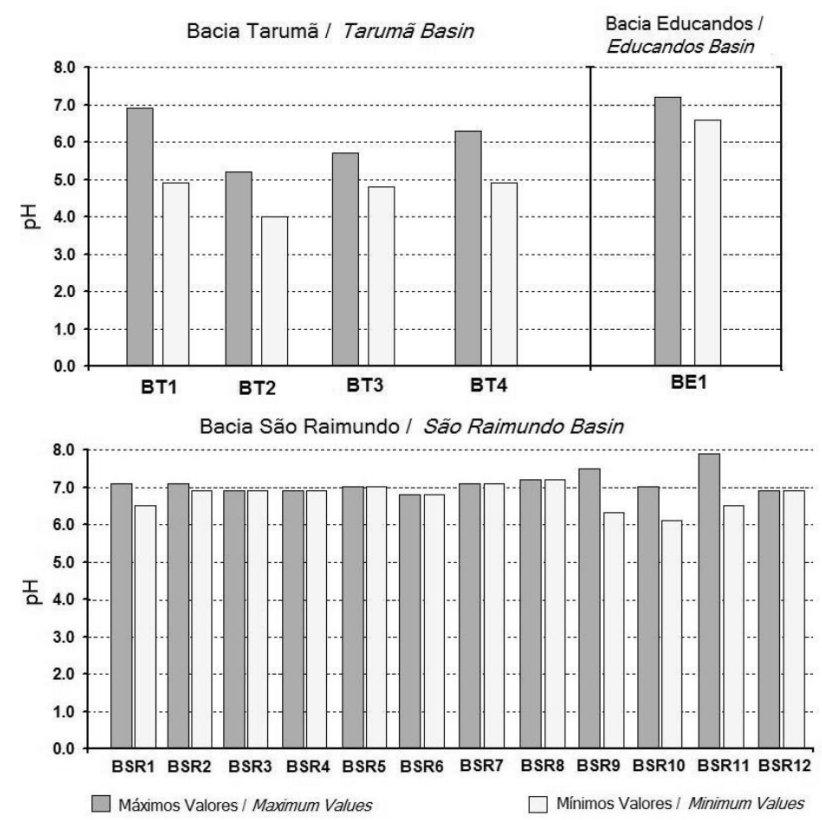

Figura 5 - Valores máximos e míminos de pH nos locais de coleta das Bacias Tarumã, Educandos e São Raimundo.
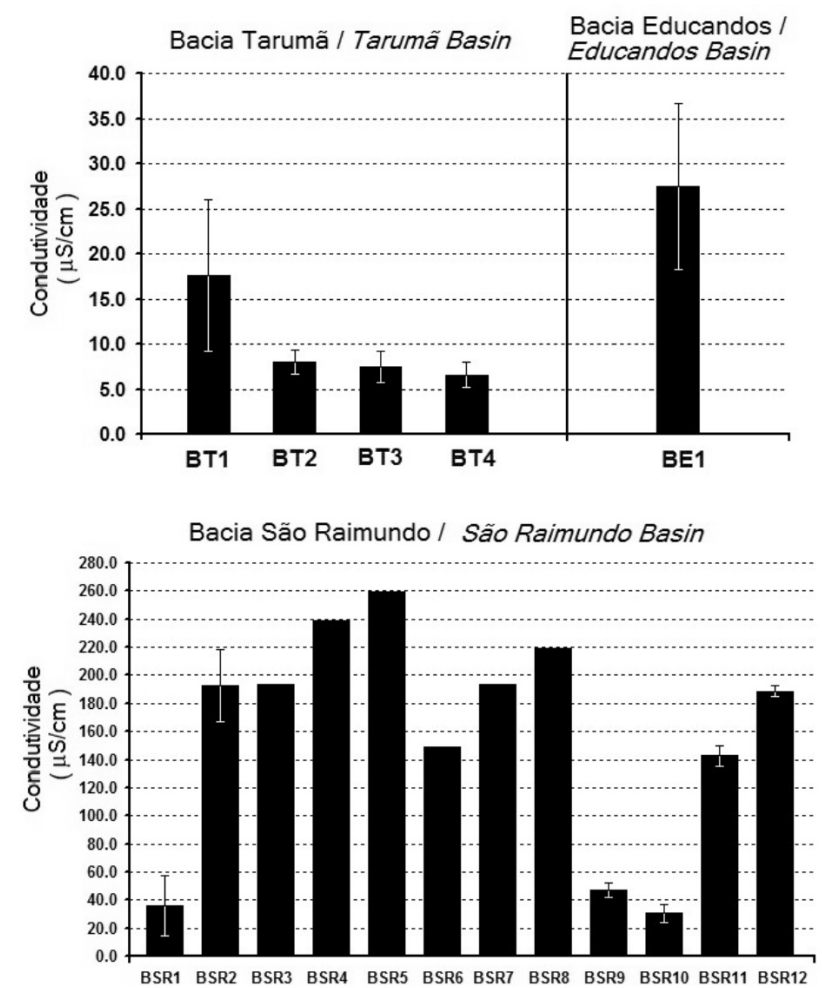

Figura 6 - Valores de condutividade (média e desvio padrão) nos locais de coleta das Bacias Tarumã, Educandos e São Raimundo. concentraçôes de oxigênio dissolvido variando de 6.4 a 8.4 mg. $\mathrm{l}^{-1}$ (Figura 7), indicando assim, que esta variável náo interferiu nas respostas de toxicidade observadas neste estudo para este sistema.
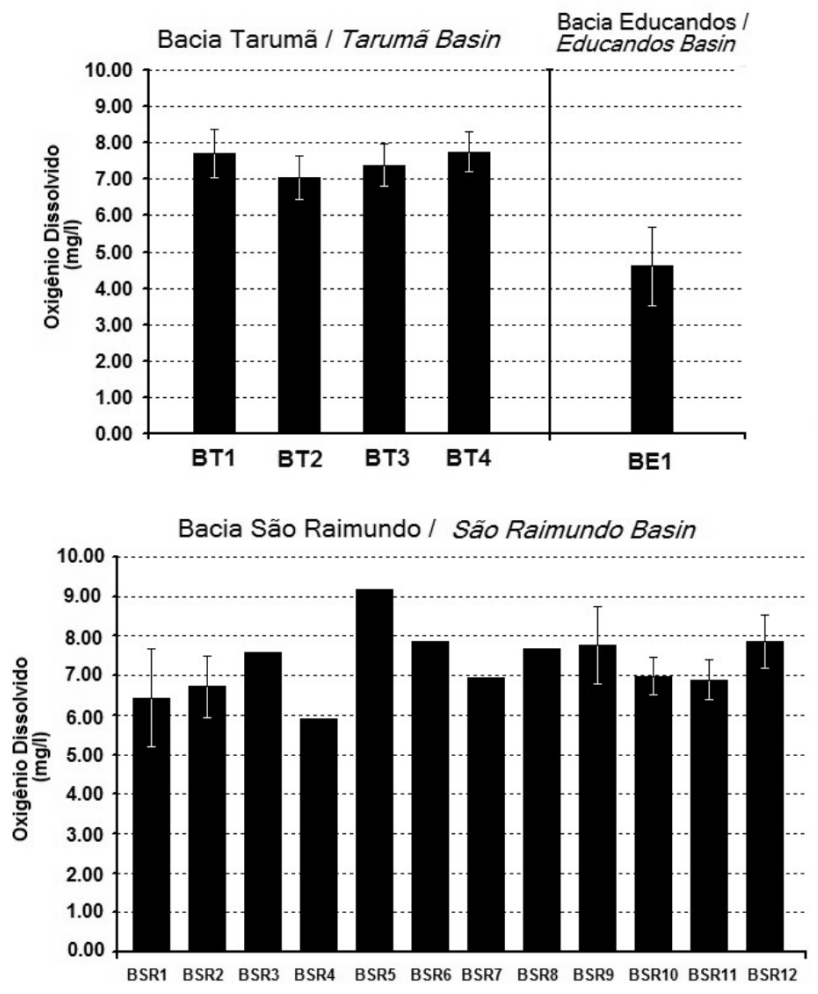

Figura 7 - Valores de oxigênio dissolvido (média e desvio padrão) nos locais de coleta das Bacias Tarumã, Educandos e São Raimundo.

O local BE1 (Igarapé do 40) pertencente a Bacia hidrográfica Educandos, é um ponto receptor de efluentes líquidos industriais e domiciliares. A variabilidade na condutividade (Figura 6) e as baixas concentraçóes de oxigênio dissolvido (Figura 7), acompanhadas de outras alteraçóes podem explicar as respostas de toxicidade (Figura 3) encontradas em parte das amostras deste sistema.

As amostras da Bacia hidrográfica Tarumã, apresentaram os menores valores para Dureza Total. Cabe destacar que os igarapés desta Bacia, apresentam águas com características mais próximas, das consideradas naturais para estes ecossistemas, onde os cátions encontram-se em equilíbrio, porém são baixos os teores de cálcio e magnésio. Nos igarapés das Bacias hidrográficas Educandos e São Raimundo, cujas águas apresentam modificaçóes em suas características originais, por efluentes com substâncias alcalinas, foram encontrados valores mais elevados para a dureza total (Figura 8).

Das comparaçóes descritivas com os parâmetros físicoquímicos, utilizados neste estudo, cabe destacar que os reflexos sobre a toxicidade, não são oriundos unicamente ao parâmetro 
em si, mas a um conjunto de interaçôes que interferem na biodisponibilidade dos contaminantes.

Quanto às origens das fontes de poluição, nos igarapés da Bacia hidrográfica São Raimundo, a contaminação é predominantemente causada por resíduos domiciliares; na Bacia hidrográfica Educandos existem emissóes de efluentes industriais e domiciliares, uma vez que seu principal tributário, o Quarenta, atravessa o Distrito Industrial de Manaus; a terceira bacia, a do Tarumã compreende áreas mistas urbana e rural, algumas industrias.
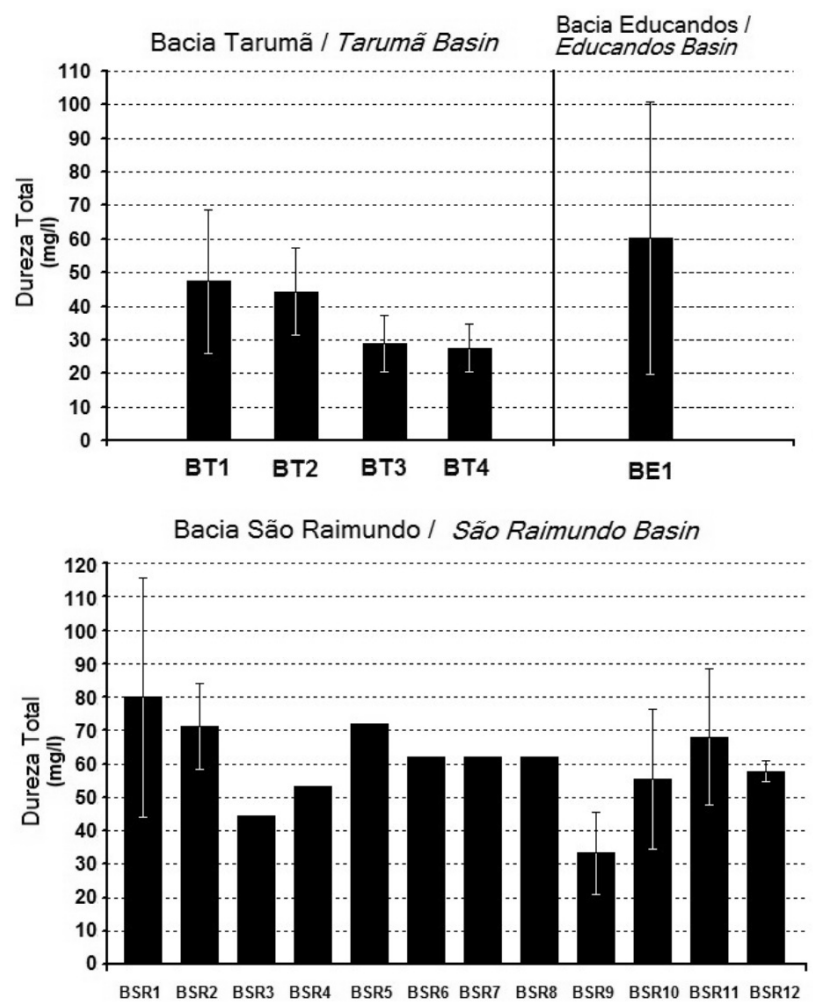

Figura 8 - Valores de dureza total (média e desvio padrão) em termos de Carbonato de Cálcio, nos locais de coleta das Bacias Tarumã, Educandos e São Raimundo.

Cabe destacar que os igarapés em Manaus formam uma densa e complexa rede de drenagem de águas, que recebe grande parte do escoamento superficial produzido pelas chuvas. Assim diferentes formas de partículas sólidas (inclusive aquelas resultantes da deposição atmosférica) e substâncias presentes nas áreas impermeabilizadas da cidade são conduzidas para esses cursos d'água.

\section{BIBLIOGRAFIA CITADA}

ABNT - ASSOCIAÇÃO BRASILEIRA DE NORMAS TÉCNICAS. 2004. NBR 12713: Ecotoxicologia aquática - Toxicidade aguda Método de ensaio com Daphnia spp (Cladocera, Crustacea).
BRASIL. 2005. Ministério do Meio Ambiente, Conselho Nacional do Meio Ambiente - CONAMA. Resolução no 357, de 17 de março de 2005.

Bringel, S.R.B. 1986. Estudos do nivel de poluiçâo nos igarapés do Quarenta e do Parque Dez de Novembro. Relatório Técnico, Instituto de Tecnologia da Amazônia/UTAM.

Campos, Z.E.S. 1994. Parâmetros físico-quimicos em igarapés de água clara e preta ao longo da rodovia BR-174 entre Manaus e Presidente Figueiredo - AM. Manaus: Dissertação de Mestrado, Instituto Nacional de Pesquisas da Amazônia / Fundação Universidade do Amazonas. 90 pp.

Cleto Filho, S.E.N. 1998. Efeitos da Ocupaçâo Urbana sobre a Macrofauna de Invertebrados Aquáticos de um Igarapé da Cidade de Manaus/AM - Amazônia Central. Manaus: Dissertação de Mestrado, Instituto Nacional de Pesquisas da Amazônia / Fundação Universidade do Amazonas.

Finney, D.J. 1952. Probit Analysis, a statistical treatment of the sigmoid response curve. 2. ed. London: Cambridge, $318 \mathrm{pp}$.

Fonseca, O.J.M.; Salem, J.I.; Guarim, V.L. 1982. Poluição e autopurificação do Rio Negro das cercanias de Manaus. Acta Amazonica, n. 12, v. 2, p. 271-278.

Junk, W.J. 1983. As águas da regiāo amazônica. In: Salati, E.;Schubart, H.O.R.; Junk, W \& Oliveira, A.E. (ed) Amazônica - Desenvolvimento, Integração, Ecologia. Brasilia: Ed. Brasiliense, CNPq. p. 45-100.

Martinez-Madrid, M. 1997. Bioensayos de Ecotoxicidad con Daphnia magna y Tubifex tubifex para la Caracterización de Sedimentos Fluviales. Bilbao: Tese de Doutorado, Facultad de Ciencias, Universidad del Pais Vasco, España.

Melo, E.G. 2003. Monitoramento Físico-Químico das Águas de Três Igarapés nas Bacias do São Raimundo, Educandos e Tarumã. Anais da XIII Jornada de Iniciaçâo Científica do PIBIC/INPA. Manaus-AM.

Melo, E.G.; Silva, M.S.R.; Miranda, S.A.F. 2005. Influência antrópica sobre águas de igarapés na cidade de Manaus - Amazonas. Caminhos de Geografia, n. 5, v. 16, p. 40-47. ISSN 1678-6343. Disponível em http://www.ig.ufu.br/revista/caminhos.html. Acesso em out/2006.

Miranda, S.A.F.; Silva, M.S.R.; Cunha, H.B \& Pinto, A.G.N. 2003. Diagnóstico da Situação dos Recursos Hídricos de Superfície, na Ârea Urbana do Município de Manaus, sob Ponto de Vista Hidroquímico. In: I Simpósio de Recursos Hidricos da Amazônia. Anais. Manaus-AM.

Rodrigues da Silva, S.L.; Santos, A.R.; Pereira, C.D.S. 2004. Tox-t, Sistema Informático para Tratamentos Estatísticos de Resultados de Testes de Ecotoxicológicos. Universidade Santa Cecília, Depto. Ecotoxicologia. Santos SP. Programa informático. 1 CD-ROM.

Schmidt, G.W. 1972. Chemical Properties os Some Water in the Tropical Forest Region of Central Amazônia Along the New Road Manaus-Caracaraí. Amazoniana, 3(2): 199-207.

Silva, M.S.R. 1996. Metais pesados em sedimentos de fundo de igarapés (Manaus - AM). Dissertação de Mestrado, Universidade Federal do Pará. 
Sioli, H. 1968. Hydrochemistry and Geology in the Brazilian Amazon Region. Amazoniana, 3: 267-277.

USEPA. 2002. Short-term methods for estimating the acute toxicity of efluents and receiving to freshwater and marine organisms. United States Environmental Protection Agency, EPA-821-R02-012. Washington, USA.

Wetzel, R.G. 1975. W.B. Saunders Company. Limnology. 743 pp.

Recebido em 21/12/2007

Aceito em 21/09/2009 